\title{
Efficacy and cost-feasibility of the Timely Chest Compression Training (T-CCT): a contextualized cardiopulmonary resuscitation training for personal support workers participating during in-hospital cardiac arrests
}

\author{
Christian Vincelette ${ }^{1,2} \cdot$ Catalina Sokoloff ${ }^{2,3,4} \cdot$ Nathalie Nadon ${ }^{2} \cdot$ Pierre Desaulniers $^{3} \cdot$ François Martin Carrier ${ }^{5,6}$
}

Received: 20 May 2020 / Accepted: 20 October 2020 / Published online: 4 January 2021

(c) Canadian Association of Emergency Physicians (CAEP)/ Association Canadienne de Médecine d'Urgence (ACMU) 2021

\begin{abstract}
Objectives The Timely Chest Compression Training (T-CCT) was created to promote more frequent training in chest compressions for personal support workers. This study aims to assess the efficacy of the T-CCT on the chest compression performance and to examine costs related to this intervention.

Methods A prospective single group, before-after study was conducted at a university-affiliated hospital. The T-CCT is adapted for support workers and lasts 20 min during working hours. Guided by peer trainers, live feedback devices and mannikins, the T-CCT targets chest compression training. Using an algorithm, chest compression performance scores were gathered before and after the intervention.

Results Of 875 employed support workers, 573 were trained in 5 days. Prior to the intervention, the median performance score was $72 \%$. Participants significantly improved after the intervention $(p<0.001)$ and the median of the differences was $32 \%$ (95\% CI 28.5-36.0). Support workers in critical care units and those with an active basic life support (BLS) certification performed better at baseline and were less inclined to have large changes in performance scores after the intervention. When compared to basic life support training, the T-CCT is over three times less expensive.

Conclusions The T-CCT was an effective and low-cost initiative that allowed to train a large group of support workers in a short amount of time. Since they are actively involved in resuscitation efforts in Quebec (Canada), it may promote the delivery of high-quality compressions during in-hospital cardiac arrests. Our inquiry can incite and guide other organizations in the implementation of similar interventions.
\end{abstract}

Keywords Cardiopulmonary resuscitation $\cdot$ Education $\cdot$ Cost-feasibility $\cdot$ Personal support workers

Electronic supplementary material The online version of this article (https://doi.org/10.1007/s43678-020-00038-y) contains supplementary material, which is available to authorized users.

Christian Vincelette

Christian.Vincelette@usherbrooke.ca

Catalina Sokoloff

Catalinasokoloff@hotmail.com

Nathalie Nadon

Nathalie.Nadon.chum@ssss.gouv.qc.ca

Pierre Desaulniers

Pierre.Desaulniers@umontreal.ca

François Martin Carrier

Francois.Martin.Carrier@umontreal.ca

1 Faculty of Medicine and Health Sciences, School of Nursing, Université de Sherbrooke, Sherbrooke, Canada
2 Learning and Simulation Center, CHUM Academy, Montréal, Canada

3 Department of Emergency Medicine, CHUM, Montréal, Canada

4 Critical Care Division, Department of Medicine, CHUM, Montréal, Canada

5 Critical Care Division, Department of Anesthesiology and Department of Medicine, CHUM, Montréal, Canada

6 Centre de Recherche du Centre Hospitalier de l'Université de Montréal (CRCHUM), Montréal, Canada 


\section{Résumé}

Objectifs Le Timely Chest Compression Training (T-CCT) a été créé pour promouvoir une formation plus fréquente en compressions thoraciques pour les préposés aux bénéficiaires. Cette étude vise à évaluer l'efficacité du T-CCT sur la performance en compressions thoraciques et à examiner les coûts liés à cette intervention.

Méthodes Une étude prospective avant-après avec un seul groupe a été menée dans un hôpital universitaire. Le T-CCT est adapté aux préposés aux bénéficiaires et dure 20 min pendant les heures de travail. Guidé par des pairs formateurs, des appareils de rétroaction en direct et des mannequins, le T-CCT cible l'entraînement des compression thoraciques. À l'aide d'un algorithme, les scores de performance en compression thoraciques ont été recueillis avant et après l'intervention.

Résultats Sur les 875 préposés aux bénéficiaires employés, 573 ont été formés en cinq jours. Avant l'intervention, le score de performance médian était de $72 \%$. Les participants se sont nettement améliorés après l'intervention $(p<0.001)$ et la médiane des différences était de $32 \%$ (IC à $95 \%, 28.5-36.0$ ). Les préposés aux bénéficiaires dans les unités de soins intensifs et ceux avec une formation de réanimation cardiorespiratoire de base (BLS) active ont obtenu de meilleurs résultats au départ et étaient moins enclins à avoir de grands changements dans leurs scores de performance après l'intervention. Comparé à la formation BLS, le T-CCT est trois fois moins cher.

Conclusions Le T-CCT était une initiative efficace et peu coûteuse qui a permis la formation d'un grand groupe de préposés aux bénéficiaires en peu de temps. Étant donné qu'ils sont activement impliqués dans les efforts de réanimation au Québec (Canada), cela pourrait favoriser la réalisation de compressions de grande qualité pendant les arrêts cardiorespiratoires en milieu hospitalier. Notre démarche pourra inciter et guider d'autres organisations dans la mise en œuvre d'interventions similaires.

\section{Clinician's capsule}

What is known about the topic?

The contribution of personal support workers in cardiopulmonary resuscitation (CPR) is important, rarely acknowledged and they are often overlooked when it is time to be trained.

\section{What did this study ask?}

What was the impact and cost of a 20-min large-scale chest compression training intervention on chest compression performance?

\section{What did this study find?}

By involving 35 peer trainers using live feedback devices and mannikins, we trained 573 workers in 5 days and report a statistically significant performance improvement.

\section{Why does this study matter to clinicians?}

Local implementation of CPR training innovations can promote high-quality chest compression by allied health personnel and can be done at a low cost.

\section{Introduction}

In-hospital cardiac arrest is a rare event associated with high mortality rates in Canada [1, 2]. High-quality chest compressions indubitably improve in-hospital cardiac arrest outcomes [3]. They require a compression rate of 100-120 per min, depth of 5-6 cm, full recoil between compressions, and adequate hand positioning [4]. However, there is important skill decay without frequent training [5].

In Quebec (Canada), compressions are often provided by personal support workers. Following mock codes at our institution, we observed poor chest compressions delivery by support workers. We suspected that barriers (e.g. staffing) explained why only one-fifth of our support workers had an active basic life support (BLS) certification.

To ensure support workers are trained in chest compressions, we adapted cardiopulmonary resuscitation (CPR) training and created an in-situ intervention, the Timely Chest Compression Training (T-CCT). The objectives of this study were to assess the efficacy of the T-CCT on chest compression performance and to examine the cost-feasibility of this training program as compared to BLS.

\section{Methods}

\section{Design and setting}

We conducted a prospective single group, before-after intervention study in a university-affiliated hospital located in Quebec (Canada). This research was approved by our institutional research ethics board.

\section{Study population}

The target population was composed of 875 support workers. They were conveniently assigned to a time slot during the 
training days and were given a choice of whether to participate or not.

\section{Intervention}

The T-CCT was designed to teach compressions in approximately 20 min (during working hours). Support workers were trained by 35 trainers (BLS trainers and professionals recognized by their peers). Trainers were first trained to ensure standardization. The intervention was conducted over five days and covered all shifts. Trainers were dispatched to one of four pods (i.e. emergency department [ED], intensive care unit [ICU], operating room [OR], and a medicalsurgical unit) and supervised a maximum of two participants at the same time.

The T-CCT had three steps. During step 1 ( $2 \mathrm{~min}$ ), participants were asked to answer three multiple-choice questions (optimal compression rate, depth, and compression/ ventilation ratio) and to perform one minute of undirected compressions [6]. Step 2 (15 min) began with a short discussion on CPR and was followed with chest compression training supervised by a trainer. This trainer used live feedback (Laerdal Medical AS, Stavanger, Norway, SkillGuide ${ }^{\circledR}$ ) and Resusci-Ann manikins (devices that create a resistance needing a $50 \mathrm{~kg}$ push to create a $5 \mathrm{~cm}$ depression) [7]. During step 3 ( $2 \mathrm{~min}$ ), participants refilled the multiple-choice questions and provided one minute of undirected compressions [6].

\section{Primary outcome}

Using an algorithm (Laerdal QCPR®), the SkillGuide® measured chest compression performance with an overall "chest compression only" score (0-100\%) [7]. This score was our primary outcome, measured during the one-minute undirected compressions in both steps 1 and 3 [6].

\section{Other variables}

We gathered sociodemographic (i.e. age, sex), and CPR training variables (i.e. years of experience, BLS certification status, and assigned unit type) through administrative databases. We suspected that working in critical care units (ED, ICU, post-anesthesia recovery room, and OR) and having an active BLS license (in the past 2 years) would be associated with greater performance scores.

\section{Statistical analyses}

We reported non-normal variables with medians and ranges (quantile 1 and 3) and others with means $(\bar{x})$ and standard deviations as descriptive statistics. Our primary analysis was to compare performance scores before and after the T-CCT with a pairwise Wilcoxon-Mann-Whitney test. The median of the differences was calculated with Hodges-Lehmann estimator.

In secondary analyses, we fitted two multivariable regression models to explore the effects of sociodemographic and CPR training variables on: (1) score differences (difference $=$ post-intervention - pre-intervention scores), and (2) post-intervention scores adjusted for pre-intervention scores. Given the non-normality of residuals, the outcome variables were converted in fractional ranks and we applied an inverse normal distribution function to provide normalized scores [8]. Regressions were performed on complete cases (539 out of 573), as there were no differences between participants with full cases and those with missing data, except for the sex variable (see Appendix 1). All analyses were conducted with R software (R core team, version 3.6.2), the alpha level was set at 0.05 , and we reported $95 \%$ confidence intervals $(95 \% \mathrm{CI})$.

\section{Cost-feasibility analysis}

We conducted a cost-feasibility analysis, where we present costs related to the T-CCT [9]. The analysis was performed by our team and informed by representatives at our institution on the budget provision related to training activities. We divided it into four sections: (1) the wage to train the trainers, (2) the wage of trainers, (3) the wage of support workers, and (4) other costs. We compared the costs of the $\mathrm{T}$-CCT to the projected budget required to train the same number of workers in BLS. Costs related to devices (e.g. mannikins) were not considered because they are used for other purposes.

\section{Results}

875 support workers were employed at the time of the intervention. Of these, 578 had training scheduled, 5 declined to participate because of a musculoskeletal ailment, and 573 accepted to participate (65.5\% of 875). Most participants were females (407 (71.0\%)). Their median age and experience were respectively 46 years (Q1-Q3, 35.8-54.0) and 8.6 years (Q1-Q3, 2.2-16.2). Most had not received BLS in the past 2 years $(436(76.1 \%))$ and were not critical care workers (441 (71.7\%)). The participants in our sample were not different from the sampling population in age ( $\bar{x} 44.7$ vs. 40.0 years), experience ( $\bar{x} 10.9$ vs. 11.0 years), and the proportion of female workers ( $71.0 \%$ vs. $73.0 \%)$. 
Table 1 Overall efficacy of the T-CCT on chest compression performance

\begin{tabular}{llr}
\hline Baseline score & & Post intervention score \\
\hline 72\% (IQR 28.0-91.0) & & $96.0 \%$ (IQR 89.0-98.0) \\
\hline Sub-group chest compression performance & & Post intervention score \\
\hline Variable & Baseline score & Critical care PSW: \\
\hline Unit type & Critical care PSW: & $96.0 \%$ (IQR 88.0-98.0) \\
& 81.0\% (IQR 47.5-95.0) & Noncritical care PSW: \\
& Noncritical care PSW: & $96.0 \%$ (IQR 91.0-99.0) \\
BLS & $69.5 \%$ (IQR 24.8-90.0) & Active certification: \\
& Active certification: & $96.0 \%$ (IQR 90.0-99.0) \\
& $75.0 \%$ (IQR 37.5-93.0) & No active certification: \\
& No active certification: & $96.0 \%$ (IQR 87.8-98.0)
\end{tabular}

IQR(Q1-Q3), $P S W$ personal support workers, $B L S$ basic life support, active certification $=$ trained in BLS in the past 2 years

\section{Efficacy analysis}

Before the intervention, the median performance score was 72.0\% (Q1-Q3, 28.0-91.0). Critical care and BLS certified participants had higher baseline scores compared to participants working in general units, and those not certified in BLS. After the intervention, the median performance score was 96.0\% (Q1-Q3, 89.0-98.0). Post-intervention scores did not differ between participants given their unit type or BLS status (see Table 1).

Our T-CCT was associated with a statistically significant improvement in performance $(p<0.001)$. The median of the differences in performance scores between the assessments was $32.0 \%$ (95\% CI 28.5-36.0).

\section{Secondary analyses}

In multivariable analysis, having an active BLS certification and working in critical care units were associated with lower normalized differences in scores. However, these variables did not influence normalized post-intervention scores, when adjusted for the pre-intervention score. Yet, participants' sex (i.e. female) and age (i.e. older) were associated with lower normalized post-intervention scores (see Appendix 2).

\section{Cost analysis}

Training support workers in BLS would be over three times more expensive as compared to the T-CCT. The cost per participant for BLS would be $173 \mathrm{CAD} \$$ as compared to 53 CAD\$ for the T-CCT (Appendix 3).

\section{Discussion}

Our study suggests that using live feedback devices in peer-led training was effective for chest compression skills acquisition. Our adapted and low-cost intervention improved performance and helped train a large group of support workers. We found that having an active BLS certification and working in critical care units were associated with greater performance at baseline. As such, this sub-group might benefit less from the T-CCT.

It is well known that CPR training improves performance [10]. Unfortunately, skill decay occurs as soon as 3 months after training $[5,10]$. Face-to-face interventions such as the T-CCT, improve CPR performance [10, 11], and recent studies have shown that using live feedback devices enhances skills acquisition [5]. However, when used in "real-world" CPR, these devices were associated with modest improvements in compressions and did not improve patient outcomes [12].

It is only recently that attention has been paid to the cost and benefit of training in healthcare [9, 13]. We provided the costs related to the T-CCT, to ensure it is reproducible and to promote its feasibility [14]. However, it does not allow us to present the T-CCT as "cost-effective", as we did not compare the performance outcomes of two interventions $[9,13]$.

\section{Clinical and research implications}

High-quality chest compressions are essential to ensure favorable outcomes [3, 15]. Replicating the T-CCT may 
help ensure providers perform high-quality compressions during resuscitation efforts. Yet, the transfer of compression skills from mannikins to the "real-world" remains unclear and is an important avenue for further research.

\section{Strengths and limitations}

First, we reported performance immediately after training. This performance might differ in other settings, or in "real-life", and it does not provide the long-term impact of our training. Second, the inclusion of support workers' wage during the intervention is arguable given that it was during working hours. Third, although our sample was representative of our target population, the external validity is limited by representing a single care centre experience. Last, the effect of differences between sex in missing data is probably minimal (less than $5 \%$ missing data).

\section{Conclusion}

Our T-CCT was an effective and low-cost initiative that allowed us to train a large group of support workers in a short amount of time. Since they are actively involved in resuscitation efforts in Quebec, it may promote the delivery of high-quality compressions during resuscitation efforts. Our inquiry can incite and guide other organizations in the implementation of similar interventions.

Acknowledgements We thank the trainers and the Direction de l'Enseignement et de l'Académie CHUM for their help in conducting the intervention.

Funding At the time of this study, CV received doctoral scholarships from the Faculty of Medicine and Health Sciences at Université de Sherbrooke, the Réseau de Recherche en Interventions en Sciences Infirmières (RRISIQ), the Canadian Institutes of Health Research (CIHR), and the Fonds de Recherche du Québec - Santé (FQR-S). FMC received a Career Award from the FQR-S. These organizations were not involved in the decision to pursue this research or to submit this article.

\section{Compliance with ethical standards}

Conflict of interest The authors declare that they have no conflict of interest.

\section{References}

1. Brindley PG, Markland DM, Mayers I, Kutsogiannis DJ. Predictors of survival following in-hospital adult cardiopulmonary resuscitation. CMAJ. 2002;167(4):343-8.

2. Schwartz BC, Jayaraman D, Warshawsky PJ. Survival From inhospital cardiac arrest on the internal medicine clinical teaching unit. Can J Cardiol. 2013;29(1):117-21.

3. Andersen LW, Holmberg MJ, Berg KM, Donnino MW, Granfeldt A. In-hospital cardiac arrest: a review. JAMA. 2019;321(12):1200-10.

4. Foundation HaS. Highlights of the American Heart Association Guidelines Update for CPR and ECC 2017. Available from: https ://www.heartandstroke.ca/-/media/pdf-files/canada/cpr-2017/ ecc-highlights-of-2015-guidelines-update-for-cpr-ecclr.ashx. Accessed 7 July 2020.

5. Zhou XL, Wang J, Jin XQ, Zhao Y, Liu RL, Jiang C. Quality retention of chest compression after repetitive practices with or without feedback devices: a randomized manikin study. Am J Emerg Med. 2020;38(1):73-8.

6. Tanaka S, Tsukigase K, Hara T, Sagisaka R, Myklebust H, Birkenes TS, et al. Effect of real-time visual feedback device 'Quality Cardiopulmonary Resuscitation (QCPR) Classroom' with a metronome sound on layperson CPR training in Japan: a cluster randomized control trial. BMJ Open. 2019;9(6):e026140.

7. Laerdal. CPR scoring explained 2019. Available from: https:// www.laerdal.com/ca/support/scoring/. Accessed 7 July 2020.

8. Templeton GF. A two-step approach for transforming continuous variables to normal: implications and recommendations for IS research. Commun Assoc Inf Syst. 2011. https://doi.org/10.17705 /1CAIS.02804.

9. Walsh K, Levin H, Jaye P, Gazzard J. Cost analyses approaches in medical education: there are no simple solutions. Med Educ. 2013;47(10):962-8.

10. Riggs M, Franklin R, Saylany L. Associations between cardiopulmonary resuscitation (CPR) knowledge, self-efficacy, training history and willingness to perform CPR and CPR psychomotor skills: a systematic review. Resuscitation. 2019;138:259-72.

11. Cortegiani A, Russotto V, Montalto F, Iozzo P, Meschis R, Pugliesi M, et al. Use of a Real-Time Training Software (Laerdal QCPR $\left.{ }^{\circledR}\right)$ Compared to instructor-based feedback for high-quality chest compressions acquisition in secondary school students: a Randomized Trial. PLoS ONE. 2017;12(1):e0169591-e.

12. Hostler D, Everson-Stewart S, Rea TD, Stiell IG, Callaway CW, Kudenchuk PJ, et al. Effect of real-time feedback during cardiopulmonary resuscitation outside hospital: prospective, clusterrandomised trial. BMJ. 2011;342:d512.

13. Walsh K. Costs and assessment in medical education: a strategic view. Perspect Med Educ. 2016;5(5):265-7.

14. Geerligs L, Rankin NM, Shepherd HL, Butow P. Hospital-based interventions: a systematic review of staff-reported barriers and facilitators to implementation processes. Implement Sci. 2018;13(1):36.

15. Duval S, Pepe PE, Aufderheide TP, Goodloe JM, Debaty G, Labarère $\mathrm{J}$, et al. Optimal combination of compression rate and depth during cardiopulmonary resuscitation for functionally favorable survival. JAMA Cardiol. 2019;4(9):900-8. 